\title{
Dissecando a masculinidade na encruzilhada entre a psicanálise e os estudos de gênero
}

Dissecting masculinity at the crossroads of psychoanalysis and gender studies

Disecando la masculinidad en la encrucijada entre el psicoanálisis y los estudios de género

Ronaldo Sousa Sampaio*

Claudia Amorim Garcia*

\begin{abstract}
Resumo
Neste trabalho, discutimos a construção da masculinidade com base na articulação entre os estudos de gênero e a leitura psicanalítica, abordagens teóricas que se afastam dos pressupostos essencialistas e enfatizam o caráter dinâmico e contingencial do masculino. Iniciamos com uma breve apresentação da posição de Judith Butler sobre gênero, e discutimos, a seguir, a abordagem psicanalítica da masculinidade representada pela pesquisa seminal de Robert Stoller e Greenson assim como pelos trabalhos de Diamond, cuja proposta teórica possibilita uma aproximação com estudos de gênero. Diamond aponta para a inevitabilidade das duplas identificações na identidade de gênero, opondo-se, portanto, à exigência da desidentificação primária defendida por Greenson, e abrindo, assim, a possibilidade de uma constituição subjetiva plural e fluida, posição semelhante aquela dos teóricos de gênero.
\end{abstract}

Palavras-chave: masculinidade; homem; gênero; psicanálise; identificação primária.

\begin{abstract}
This article focuses on the construction of masculinity based on the articulation between gender studies and psychoanalysis, theoretical approaches which refute essentialist assumptions and emphasize the dynamic and contingent nature of masculinity. Starting with a brief presentation of Judith Butler's concept of gender, it discusses the psychoanalytic view of masculinity represented by Stoller's and Greenson's seminal research, as well as by Diamond's studies, whose
\end{abstract}

Texto recebido em outubro de 2009 e aprovado para publicação em maio de 2010.

* Doutor pelo Programa de Pós-graduação em Psicologia Clínica da PUC Rio, psicanalista. E-mail: ronaldopsi@terra.com.br.

** Doutora em Psicologia pelo The Wright Institute, Berkeley, EUA, professora associada do Departamento de Psicologia da PUC Rio. E-mail: clauag@uol.com.br. 
theoretical perspective allows a connection with gender studies. Diamond acknowledges the inevitability of double identifications in the development of gender identity, and denies the need for primary deidentification suggested by Greenson, thus pointing out the possibility of a plural and fluid process of psychic construction, a theoretical approach similar to gender theories.

Key-words: masculinity; man; gender; psychoanalysis; primary identification.

\section{Resumen}

En este trabajo discutimos la construcción de la masculinidad a partir de la articulación entre los estudios de género y la lectura psicoanalítica, abordajes teóricas que se alejan de los presupuestos esencialistas y enfatizan el carácter dinámico y contingencial de lo masculino. Iniciamos con una breve presentación de la posición de Judith Butler sobre género, y discutimos, a continuación, el abordaje psicoanalítico de la masculinidad representada por la investigación seminal de Robert Stoller y Greenson, así como por los trabajos de Diamond, cuya propuesta teórica posibilita una aproximación con estudios de género. Diamond apunta para lo inevitable de las dobles identificaciones en la identidad de género oponiéndose, por lo tanto, a la exigencia de la desidentificación primaria defendida por Greenson, y abriendo, así, la posibilidad de una constitución subjetiva plural y fluida, posición semejante a aquella de los teóricos de género.

Palabras-clave: masculinidad; género; psicoanálisis; identificación primaria.

\section{Dissecando a masculinidade na encruzilhada entre a psicanálise e os estudos de gênero}

A psicanálise tem tradicionalmente considerado a mulher como seu grande enigma, um continente negro, cuja tentativa de elucidação tem estimulado uma produção teórica extremamente diversificada e representa o esforço até hoje infindo de conseguir explicar as peculiaridades do feminino. Esse interesse já secular da psicanálise de desvendar a singularidade das mulheres não se fez acompanhar de um movimento semelhante em relação aos homens, o que acabou por relegar a um plano infinitamente inferior a tarefa de compreender as idiossincrasias do masculino. Assim, o homem tendeu a ser compreendido como sendo mais simples e menos misterioso, apresentando um processo de constituição subjetiva teoricamente menos engenhoso (Freud, 1925). Desde os estudos de Stoller e Greenson, nos anos 60, contudo, esse 
mito começou lentamente a ser questionado pela psicanálise, dando ensejo à aparição cada vez mais frequente de estudos sobre masculinidade nesse campo, até chegarmos ao quadro atual, no qual os estudos psicanalíticos sobre os homens já estão fortemente difundidos nos Estados Unidos e são um tema recorrente de pesquisas também na Europa e no Brasil.

Os estudos sobre o homem e a mulher empreendidos pela psicanálise, entretanto, de uma maneira geral, foram prejudicados por conta da recorrente tendência dos seus teóricos de desprezar a contribuição de outras disciplinas. Contemporaneamente, no entanto, vêm surgindo estudos psicanalíticos acerca do masculino e do feminino com base em uma ótica interdisciplinar. Sob esse prisma, a masculinidade passou a ser entendida como uma questão que requer a atenção dos psicanalistas, mas cujo entendimento exige também uma leitura pela ótica das demais ciências humanas e sociais, valiosa para a compreensão do tema em questão. Nesse sentido, uma articulação entre a psicanálise e os estudos de gênero têm se mostrado particularmente interessante na pesquisa da subjetividade masculina, questionando o mito do homem "took for granted", que historicamente acabou por prejudicar a investigação sobre a masculinidade. Esse trabalho tem o objetivo de aproximar as duas abordagens, utilizando-se, para tanto, das contribuições de J. Butler, representando os estudos de gênero, e M. Diamond, psicanalista americano, que vem aprofundando-se no estudo da masculinidade.

\section{Gênero: uma construção histórica}

Os estudos de gênero se propagaram na academia com mais força a partir dos anos 70, atrelados às muitas correntes do movimento feminista, constituídas majoritariamente por autoras das ciências sociais, com o intuito recorrente de entender e questionar a posição de subordinação da mulher em relação ao homem nas sociedades contemporâneas (Machado, 1992). Em seu início, gênero era quase equivalente a mulher, dada a preponderância de temas relativos ao feminino elencados pelos estudiosos desse campo. Contemporaneamente, contudo, essas pesquisas abrangem uma problemática mais ampla, sendo usadas, inclusive, para o alcance de uma melhor compreensão sobre a constituição subjetiva masculina (Diamond, 2004; Ceccarelli, 1998) e, separando as categorias de sexo e gênero, questionam ou até mesmo rejeitam explicações biológicas (Butler, 1990).

Assim, os estudos de gênero privilegiam a "dimensão de escolha cultural pretendendo descartar alusóes a um atavismo biológico para explicar as feiçóes 
que o feminino e o masculino assumem em múltiplas culturas" (Heilborn, 2004). Nessa perspectiva, a estabilização dos modelos de masculinidade e de feminilidade predominantes em uma determinada sociedade só se dá por meio do aprendizado das funções e pela internalização das representações de gênero instituídas pela cultura. Os estudos sobre gênero partem, portanto, do pressuposto de que a contribuição da biologia é insuficiente para a compreensão das diferenças subjetivas existentes entre homens e mulheres (Sorj, 1992) e se apoiam num argumento construtivista para fundamentar suas conclusões.

A expansão dos estudos acerca das questões de gênero é comumente relacionada à emergência da Pós-modernidade e o concomitante fim da crença nas metanarrativas modernas (Kumar, 1995). Associa-se o interesse crescente nesse campo ao intuito cada vez maior, nas ciências humanas e sociais, de abordar o particular em detrimento do universal, decorrente da falência do projeto salvacionista moderno e do questionamento da noção de verdade absoluta (Lyotard, 1979; Giddens, 1999). Assim, considera-se que "o império da subjetividade e da relativização assume lugares cada vez mais consolidados” (Silva, 2004, p. 3). Foi nesse novo contexto epistemológico que os estudos de gênero proliferaram, tendo, nos últimos 50 anos, se desmembrado em diversas correntes que, no entanto, apresentam em comum a tentativa de escapar das armadilhas da naturalização e construir um pensamento capaz de demonstrar como os modelos de feminilidade e masculinidade são construídos culturalmente, e o quanto as identidades de gênero se apoiam nos ideais daí oriundos. Bento (2006), contudo, destaca que há também diferenças significativas entre as teorias seminais desse campo de pesquisa que podem ser agrupadas em três tendências explicativas da construção das identidades de gênero: universalista, relacional e plural (Bento, 2006, p. 69).

A perspectiva universalista foi adotada e adquiriu maior destaque na academia com as publicaçôes de Simone de Beauvoir, notadamente com seu livro O segundo sexo (1949). Sob o olhar dessa escritora, a mulher não nasce, porém se torna (Beauvoir, 1949). Embora tenha tido o mérito de ter sido uma das primeiras autoras a desnaturalizar a condição da mulher, Beauvoir falhou, segundo Bento (2006), por compreender os gêneros a partir de oposições binárias, mesmo que tenham sido consideradas como formações historicamente constituídas. Nesse sentido, seu erro foi supor a existência de características unificadoras existentes entre os homens e as mulheres, capazes de fazerem deles dois grupos distintos, mas com membros homogêneos entre si. Esse enfoque desconsidera as diferenças existentes entre os integrantes de 
cada grupo e, desse modo, sua análise é característica, ainda, das divisões antitéticas características do pensamento moderno (Bento, 2006).

Com Joan Scott, emergiu uma nova proposta de pensar o gênero, com base em uma perspectiva relacional, bastante recorrente desde a publicação de seu clássico artigo Gênero: uma categoria útil para a análise histórica (1986). Sob esse prisma, homem e mulher se definem um em função do outro, de acordo com uma ótica sistêmica. Assim, as significações de poder e o gênero são relacionados e considerados como tendo sido historicamente erigidos desde uma lógica desigual que coloca o homem numa posição de dominação em relação à mulher. Essa dinâmica, para Scott (1986), estaria presente em todas as esferas da vida social, constituindo-as, ainda que parcialmente (Silva, 2004). Assim, a perspectiva de gênero de Scott "reconhece a sua dispersão, o que o faz presente nos símbolos e nas representações culturais; nas normas e nas doutrinas, nas instituições e organizações sociais; nas identidades subjetivas" (Silva, 2004, p. 5). Nesse sentido, o questionamento das relaçôes de gênero implicaria em pôr em xeque, consequentemente, o sistema como um todo. Sua abordagem, já inspirada na visada pós-estruturalista de autores como Foucault e Derrida, aponta para o fato de que

\section{[...] Homem e mulher são categorias vazias e transbordantes; vazias porque elas não têm um significado definitivo e transcendente; transbordantes porque, mesmo quando parecem fixadas, elas contêm ainda dentro delas definições alternativas negadas ou reprimidas (Scott, 1986, p. 1074). ${ }^{1}$}

As concepções de masculinidade e a feminilidade são, portanto, resultantes das relaçôes de poder e, por conta disso, sempre variáveis.

O ponto falho na abordagem de Joan Scott está, para Bento (2006), na sua compreensão do caráter relacional do gênero desde a diferença sexual, o que aproxima sua visada de um pressuposto binário. Nesse sentido, sua proposta não favorece uma discussão que inclua as sexualidades desviantes, pois o binarismo acaba por se tornar uma forma modelar e heterossexista de entendimento dessa questão.

Judith Butler (1990), representante da tendência plural, propóese, então, a superar os limites dos estudos de gênero que tendiam a estar calcados no heterossexismo e, por conta disso, davam poucos subsídios para a legitimação de outras formas de subjetivação. Sua proposta foi, portanto, demonstrar o quanto os movimentos feministas se fragilizavam

Tradução de Cristina Rufino Dabat e Maria Betânia Ávila. Disponível em: <www.dhnet.org.br>. Acesso em: 10 jan. 2009. 
por apoiarem-se em concepções de gênero unitárias, que pressupunham, necessariamente, a existência de um sujeito do feminismo. Partindo de uma premissa diametralmente oposta, a autora passa a defender que "o gênero é uma complexidade cuja totalidade é permanentemente protelada, jamais exibida em qualquer conjuntura considerada" (Butler, 1990, p. 37). Nesse sentido, o gênero passa a ser entendido como uma ficção e, por conta disso, qualquer noção de identidade de gênero é ilusória. Logo, não existe a mulher, porém mulheres. Com essa visada, a autora americana passou do plano relacional ao plural nos estudos de gênero, com a intenção de questionar o tabu da heterossexualidade compulsória vigente na cultura e entender e reconhecer as denominadas identidades queer (Butler, 1990, p. 177), aquelas marginalizadas em nossa sociedade e cuja forma de constituição desestabiliza o padrão normativo, como as drag queens, os transexuais e os casais de gays e lésbicas. Ao pensar no gênero como plural, Butler não apenas inaugurou uma nova forma de pensar o feminismo e os problemas de gênero, mas abriu uma brecha para repensarmos a constituição da feminilidade e, também, da masculinidade.

\section{Judith Butler e a ficção de gênero}

Judith Butler (1990) é uma representante do denominado movimento pós-estruturalista nas ciências humanas. Autores dessa corrente costumam recorrer à abordagem desconstrutivista de Derrida (Arán, 2006) ou à leitura foucaultiana de Nietzsche, sendo Butler uma seguidora desta última tendência. Segundo Butler (1990), o gênero é uma construção social tributária da forma como o poder atua produzindo e regulando os corpos em conformidade com a ideologia vigente nas sociedades. É, antes de mais nada, uma ficção, um modelo de constituição subjetiva e conduta social produzido culturalmente e que se torna distintivo do humano. Assim, a cultura insere nos corpos essa marca, produzindo a ficção de uma identidade estável e coerente. Nesse sentido, a estabilidade e coerência do gênero são ilusóes sustentadas socialmente e que tornam mais eficaz a regulação cultural dos corpos (Butler, 1990).

O pensamento de Butler (1990) se apoia na rejeição ao conceito de origem (Ursprung), posição inaugurada por Nietzsche e retomada por Foucault (1979) em Microfísica do poder. O filósofo francês, ao se apropriar dessa visada antiessencialista, pretende se opor à metafísica e fundamentalmente ao estruturalismo, que marcou o cenário intelectual europeu dos anos 60 . Seu intuito é, então, o de tecer um olhar genealógico sobre a História que se desenrola sempre como um embate de forças e não contém uma verdade 
inscrita na sua origem. Sua argumentação privilegia o apontamento da descontinuidade, já que a História se inscreve no corpo social e no corpo físico, que existem apenas em estados permanentemente inacabados (Foucault, 1979). A ideia da existência de uma unidade como o Eu é, para Foucault, não mais que uma quimera, já que o caracteriza o corpo é a sua permanente fragmentação. Os acontecimentos históricos criam ilusões de estabilidade, e o corpo existe, portanto, apenas como "um volume em perpétua pulverização" (1979, p. 22).

Judith Butler (1990), então, se apoia na teoria foucaultiana para forjar sua concepção da função do gênero na construção da identidade (para ela, sempre ilusória). Se o corpo é marcado historicamente, não pode ser estável, já que a História é descontínua. Dentre as múltiplas marcas que a cultura impõe sobre os corpos, Butler destaca o gênero como a inscrição primeira, inauguradora do processo de subjetivação. Assim, o gênero pode ser compreendido como sendo parte fundamental e primeva da construção, sempre inacabada, do que se convenciona chamar de "pessoa" e, desse ponto de vista, não há uma identidade anterior àquilo que os cientistas sociais denominam "identidade de gênero".

Seria errado supor que a discussão sobre a "identidade" deva ser anterior à discussão sobre a identidade de gênero, pela simples razão de que as "pessoas" só se tornam inteligíveis ao adquirir seu gênero em conformidade com padróes reconhecíveis de inteligibilidade de gênero (Butler, 1990, p. 37).

O gênero é formador identitário pelo fato de o sujeito ser educado em concordância com o sexo que lhe é atribuído no nascimento ou mesmo antes. É o gênero que marca o sujeito como humano, com base na distinção primitiva quanto a ser ele homem ou mulher. Por conta disso, Butler (1990) afirma que "a marca do gênero parece qualificar os corpos como corpos humanos; o bebê se humaniza no momento em que a pergunta 'menino ou menina?' é respondida" (1990, p. 162).

Essa identidade de gênero só se constrói (sempre fragilmente) pela repetição insistente das performances prototípicas de seu sexo. É, portanto, apenas pela ação que são internalizados os imperativos convencionados. Nesse sentido, Butler explicitamente se mostra herdeira das teorias genealógicas nietzschiana e foucaultiana, rechaçando a ideia da preexistência de qualquer essência masculina, e considerando, ao contrário, que aquilo que forma uma ilusão de coerência e continuidade no sujeito é o gênero, conforme ele é concebido por meio de suas práticas reguladoras de formação e divisão. Ser um homem ou 
ser uma mulher é o resultado final de um processo imitativo das performances masculina e feminina construídas pela cultura ao longo da história (Butler, 1990). Dessa forma, o corpo é "uma fronteira variável, uma superfície cuja permeabilidade é politicamente regulada (1990, p. 198)", e que está aberta permanentemente para receber as marcas da cultura. Exatamente pelo fato de essa permeabilidade ser insuperável, a política adotada pelas mais distintas sociedades foi a de tentar tornar incontestável a visão oposta, a da continuidade e coerência do gênero. Sustentar essa ilusão de constância tem como um de seus efeitos a diminuição da possibilidade de contestação da divisão dos papéis de gênero, com base na naturalização das relações entre os sexos.

Apoiando-se em Foucault, para quem a pesquisa da origem das coisas só faz revelar "o segredo de que elas são sem essência, ou que sua essência foi construída peça por peça a partir de figuras que lhe eram estranhas" (Foucault, 1979, p. 18), Butler demarca que não há um modelo original a ser copiado, de modo que toda imitação não deixa de ser uma cópia da cópia. Imita-se um modelo historicamente construído e que, por causa disso, pode variar ao longo da história das sociedades. Logo, a identidade de gênero se forma pela repetição performativa, ao longo da vida, de modelos fornecidos pela cultura geradores de uma ilusão de identidade.

No lugar de uma identificação original a servir como causa determinante, a identidade de gênero pode ser reconcebida como uma história pessoal/cultural de significados recebidos, sujeitos a um conjunto de práticas imitativas que se referem lateralmente a outras imitações e que, em conjunto, constroem a ilusão de um eu de gênero primário e interno marcado pelo gênero, ou parodiam o mecanismo dessa construção (Butler, 1990, p. 197).

A imitação exaustiva dos modelos normativos não garante a constituição de uma estrutura sólida, mas, ao contrário, resulta na formação de uma identidade de gênero sempre instável.

Se usarmos o pensamento de Butler como suporte para a compreensão do masculino, podemos considerar que sua teoria acaba por afirmar a inexistência de uma essência masculina que leve o homem a se comportar espontaneamente de forma viril. Assim, a forma final da masculinidade se dá pela prática reiterada das performances de gênero, que têm efeitos substancializantes (Butler, 1990). Ao se referir a efeitos substancializantes, em vez de proclamar a constituição de uma substância, Butler busca afirmar a contingência da identidade de gênero, a qual tem seu efeito substantivo "performativamente produzido e imposto pelas práticas reguladoras da coerência do gênero" (Butler, 1990, p. 48) que não garantem nenhuma estabilidade substancial já que "não há identidade de 
gênero por trás das expressões de gênero; essa identidade é performaticamente constituída, pelas próprias expressões tidas como seus resultados" (Butler, 1990, p. 48). Nesse sentido, múltiplas são as possibilidades de subjetivação. $\mathrm{O}$ fato de classificarmos os gêneros como masculino ou feminino é o corolário do esforço empreendido pela sociedade para manter viva essa estrutura dual, considerando-se que, na origem, não há qualquer marca diferenciadora dos sujeitos (a não ser aquelas impostas pela cultura).

Butler (1990) contribui para a discussão sobre gênero fora do modelo binário e universalizante predominante no Ocidente e absorvido de forma acrítica por boa parte do movimento psicanalítico. Suas conclusões teóricas chocamse claramente com concepções biologizantes das problemáticas de gênero e, também, com interpretaçôes lacanianas da questão da diferença sexual. Na sua perspectiva, os papéis de gênero são inventados, pois nada na origem do menino ou da menina indica que seu destino será assumir os papéis masculino ou feminino que a sociedade destaca para cada um dos sexos. Nesse sentido, a biologia não define o humano, necessariamente plástico e, consequentemente, múltiplas são as suas possibilidades de constituição subjetiva.

O pensamento de Butler é característico do momento contemporâneo de emergência do questionamento da tradicional divisão entre os papéis de gênero, no qual o paradigma falocêntrico é posto em questão, e pode se mostrar útil na problematização da masculinidade hoje, principalmente na aproximação com algumas contribuições da psicanálise.

\section{Uma leitura psicanalítica da masculinidade}

Um ponto que permeia os estudos sobre o masculino, e que acaba por marcar as diferentes abordagens teóricas é o uso, ou não, de categorias universais para pensar a masculinidade. Por sua filiação ao pensamento de Foucault e Nietzsche, Judith Butler (1990) recusa-se a conceber que haja invariantes no processo de construção das identidades de gênero. Assim, é a cultura que molda os corpos, sendo o recurso à biologia inadequado para justificar as diferenças existentes entre os homens e as mulheres. Nesse sentido, sua posição teórica se choca frontalmente com abordagens cientificistas que defendem que a masculinização se dá naturalmente, como resultado do amadurecimento biológico do indivíduo.

Recentemente, autores do campo da neurociência têm partido com grande frequência de premissas deterministas e sustentado que a genética é capaz de, por si só, explicar as diferenças existentes entre os homens e as mulheres. Para Russo, "a neurociência vem propor uma leitura radicalmente 
naturalizante e materialista da mente humana" (2002, p. 346), embalada pela posição hegemônica que o paradigma da biologia ocupa atualmente no meio científico. O psicólogo e professor de Harvard, Steve Pinker, é um típico representante dessa linha de pesquisa e afirma que seus estudos levam à constatação de que, por razóes evolutivas, os cérebros feminino e masculino são diferentes. As características atuais do humano teriam sido herdadas de seus ancestrais por conta da necessidade que eles tiveram de se adaptar ao meio ambiente, anteriormente à invenção da agricultura e à industrialização. Os padrões atuais de comportamento, as formas de sentir e o paladar teriam se constituído, portanto, nessa fase mais inóspita da humanidade, selando um destino para os indivíduos. Os cérebros dos homens e das mulheres têm, por conta disso, habilidades distintas, e o principal fator responsável por tais características é a ação da testosterona no cérebro já na fase uterina, fomentando alterações neurais. Essas mudanças também são geradas por hormônios no período da puberdade e determinam nossas diferenças biológicas. Sob esse prisma, podemos pensar que a construção da masculinidade está muito mais fortemente atrelada a fatores inatos do que a influências da sociedade. As formas que os gêneros e, particularmente, os homens assumem em nossa cultura são, assim, geneticamente determinadas.

Temos, então, aqui duas posições antagônicas. Aquela que afirma ser a masculinidade uma "invenção" da cultura (Butler, 1990), e outra que afirma ser a masculinidade efeito de forças orgânicas inerentes aos sujeitos de sexo masculino (Pinker, 2006). Uma terceira posição seria aquela representada pela psicanálise. Nessa seara, as opções são muitas, e diferentes serão os encaminhamentos se optamos por embasar nossos argumentos em representantes da escola francesa, normalmente remetidos a Freud ou Lacan, ou se escolhemos como suporte o pensamento dos psicanalistas anglo-americanos, que se derivam das contribuições de Winnicott e Klein.

A escola francesa, no rastro da orientação lacaniana, costuma apoiar suas conclusões sobre a construção da masculinidade nos efeitos do complexo de Édipo e da introdução da lei do pai pela metáfora paterna (Lacan, 1958) na constituição subjetiva. Nesse sentido, as trajetórias masculinas teriam sua etiologia localizada fundamentalmente na especificidade da dinâmica triangular, na sua dissolução e nas identificações que daí resultam, cujos efeitos são estruturantes para o psiquismo. A abordagem desse tema pela via da sexualidade edípica implica a ausência de uma distinção clara entre sexo e gênero, estando suas conclusóes sobre a masculinidade apoiadas nos destinos da sexualidade infantil. 
A leitura dos textos freudianos sobre o complexo de Édipo escritos na década de 1920, de fato, não nos deixa dúvidas sobre a importância da dinâmica edípica e do processo de identificação para a constituição da masculinidade. Mesmo antes desse período, na década de 1910, quando a discussão sobre o conceito de Édipo era ainda incipiente, Freud já considerava que as perturbações da sexualidade masculina adulta emergiam como efeitos a posteriori da fixação no amor primevo pela mãe, somadas às frustrações que a realidade impunha no momento da escolha do objeto de amor na vida adulta. A fixação no Édipo seria a explicação para as dificuldades existenciais dos homens e, especialmente, para os empecilhos na vida amorosa. A masculinidade estaria atrelada ao abandono da mãe como objeto incestuoso e à identificação com modelos masculinos. Esses modelos introjetados e outros que se apresentariam ao longo da vida tornar-se-iam a base da construção do sentimento de masculinidade, que só se configuraria, entretanto, de forma mais arrumada, com a chegada da puberdade, depois de um longo período de latência da sexualidade (Freud, 1905).

Se, por um lado, é inegável a importância do Édipo para o entendimento da constituição subjetiva masculina, por outro, a dissecação dessa dinâmica é insuficiente para a compreensão da configuração da masculinidade, assim como, também, para o estudo da psicopatologia dos homens. Dessa maneira, é fundamental a consideração das formulações feitas por estudiosos do préÉdipo, que dão relevo à influência dos períodos mais primitivos do psiquismo na configuração subjetiva do homem. Dentre eles, o americano Robert Jesse Stoller (1985) se destacou pela investigação minuciosa das vicissitudes inerentes a esse período mais primitivo, considerado por ele tão importante para a constituição subjetiva masculina quanto a fase edipiana, já que, naquele momento primevo, configurava-se uma dinâmica, cuja superação era fundamental para a constituição da virilidade, e que se apresentava essencialmente na relação inicial indiferenciada mãe-bebê.

Em Freud, o conceito da existência de um sentimento de união primitiva entre o eu e o mundo externo aparece em o Mal-estar na civilização (1930), quando ele admite que a experiência de uma separação existente entre o eu e o meio ambiente não se apresenta para a criança desde o início. Será a percepção do prazer e do desprazer provocados por certos estímulos que fará com que o bebê diferencie seu eu do mundo externo, conforme ele percebe que não tem o domínio sobre certos prazeres e desprazeres que se originam do exterior. Tal separação é o primeiro passo no sentido da introdução do princípio de realidade, sendo, portanto, fundamental para o psiquismo, embora o estado de união com o mundo externo nunca seja superado totalmente, e venha a 
ser revisitado no fenômeno religioso e na experiência da paixão (Freud, 1930) sob a forma de um "sentimento oceânico" (Freud, 1930, p. 90).

Embora admita a existência dessa união primitiva e a considere importante para o entendimento da construção do eu, Freud não a utiliza como ferramenta fundamental para a compreensão da constituição psíquica nem das neuroses que têm no complexo de Édipo o seu núcleo. Esse sentimento de união primevo não assume em Freud, portanto, a importância teórica que adquirirá mais tardiamente. À época de Freud, coube a Ferenczi (1924) desenvolver essa problemática de forma mais elaborada na compreensão da sexualidade, em especial no entendimento do ato sexual nos homens.

Em 1924, Ferenczi (1924) se referiu ao desejo do humano de retornar ao estado de indiferenciação original, em Talassa. Nesse texto, considera o nascimento um momento de forte angústia para o bebê, que sai de um ambiente de proteção e depara um mundo hostil para o qual ele está, a princípio, despreparado, o que invoca desamparo. Nesse momento quebra-se um estado de união mãe-bebê que, entretanto, ficará para sempre marcado psiquicamente, ensejando buscas de retorno simbólico à unidade primária. O desenvolvimento da sexualidade constituir-se-ia, então, como uma busca paulatina de retorno a esse estado inicial no útero, desde a sua forma oral mais remota até o ato sexual genital, no qual o eu identificar-se-ia com o pênis e as secreçōes e realizaria, simbolicamente, o retorno à indiferenciação original.

Se considerarmos toda a evolução da sexualidade... e se tivermos em mente os processos complexos de identificação do ego com o pênis e com a secreção genital, chegaremos à conclusão de que toda essa evolução, incluindo, por conseguinte, o próprio coito, só pode ter por objeto final uma tentativa do ego... de regressar ao corpo materno, situação em que a ruptura tão dolorosa entre o ego e o meio ambiente não existia ainda (Ferenczi, 1990, p. 24).

Para Ferenczi (1924), portanto, o ato sexual proporciona ao homem a realização simbólica do retorno ao interior do corpo materno, sendo por isso uma experiência de extremo prazer. $\mathrm{O}$ regresso ao útero representa o mais forte desejo humano, e sua realização simbólica se dá pela identificação com o próprio pênis e a penetração no corpo feminino.

A postulação segundo a qual o homem constitui-se desde uma ruptura com um estado fusionado original não foi um insight ferencziano. Já no discurso de Aristófanes, em $O$ Banquete, encontramos a definição do amor como o retorno a um estado primitivo de fusão, no qual dois corpos correspondem a um só. Também a psicanálise entende a paixão como um estado no qual as 
fronteiras egoicas sofrem ameaça de dissolução (Freud, 1930), o que ocasiona um sentimento de unidade. Como num retorno à fusão primitiva, "contra todos os seus sentidos, um homem que se ache enamorado declara que eu e tu são um só, e está preparado para se conduzir como se isso constituísse um fato" (Freud, 1930, p. 83).

A temática da indiferenciação primeira se mostrou particularmente relevante para a discussão sobre a constituição da identidade de gênero e foi exaustivamente trabalhada com esse objetivo por Robert J. Stoller, psicanalista americano que se dedicou a estudar a construção da feminilidade e da masculinidade a partir dos anos 1960. Stoller (1985), seguindo Mahler (1975), parte do princípio da existência de uma simbiose primitiva (Stoller, 1985, p. 35) entre mãe e bebê para explicar a formação da identidade de gênero no menino. No momento mais precoce de vida, o bebê não se diferencia da mãe, estando, portanto, num estado de fusão que só será superado após alguns meses. Stoller (1985), diferentemente de Ferenczi, desconsidera a união prénatal entre mãe e bebê e afirma que a fusão primitiva se dá essencialmente na amamentação, no momento em que a intimidade entre a criança e sua cuidadora é maior. Essa união primeva será primordial para a formação do psiquismo, sendo fundamental que a mãe a exerça, em termos winnicottianos, de forma suficientemente boa, deixando que haja frustrações, porém dentro de limites toleráveis (Stoller, 1985).

Esse momento inicial é um período de extrema importância para a constituição da subjetividade masculina, pois dessa simbiose primitiva emergirá uma identificação com o ente materno, modulada pela entrada ou não de um terceiro, que deve barrar a fusão e se oferecer, também, como objeto de identificação. Stoller (1985) inova ao postular que a identificação primária do menino se dá com a mãe, portanto no campo do feminino, o que significa que "a masculinidade nos homens não é simplesmente um estado natural que precisa ser apenas preservado para desenvolver-se sadiamente; ao contrário, ela é uma conquista" (Stoller, 1985, p. 35). Para que seja aberto o acesso do menino à masculinidade, é preciso que a mãe aceite que o estado fusionado inicial não pode se prolongar indefinidamente e permita que outras linguagens, além da materna, possam ser incorporadas pela criança (Stoller, 1985, p. 35). Mães cuja condição de mulher não foi valorizada por seus ascendentes, principalmente na fase dos cuidados primários, gerando um desejo reativo de ser menino, apresentam muita dificuldade em se separar de seus filhos. Nesses casos, ao terem um filho de sexo masculino, muitas vezes se tornam excessivamente fundidas a ele, encenando seu desejo de ser o menino que seus pais esperavam que ela fosse. Segundo Stoller (1985), quando, além 
desse fator, há também um pai ausente que não facilita a separação mãe-filho, tem-se um quadro de "excesso de feminilidade e carência de masculinidade" (Stoller, 1985, p. 36) e, eventualmente, podem aparecer dificuldades para a assunção de uma posição viril. Por outro lado, se a mãe demonstra dificuldades em se entregar à fusão inicial seu filho, pode vir a apresentar uma certa carência de feminilidade, o que poderá dificultar sua dinâmica afetiva e torná-lo excessivamente masculino e propenso a erigir defesas fálicas (Stoller, 1985, p. 24). É necessário, portanto, que nesse momento inicial possam simultaneamente desenvolver-se no menino e serem acolhidos pelos pais a afeição pela mãe e o desejo de diferenciação, requisitos essenciais para a constituição da masculinidade e para o desenvolvimento da afetividade.

Diferentemente de Freud, que parece naturalizar o processo de construção da masculinidade ao considerá-la mais simples se comparada ao caminho que conduz a menina à feminilidade (Freud, 1931, 1933), Stoller afirma ser igualmente trabalhoso a trajetória do menino rumo à masculinidade, opinião compartilhada por autores como Greenson (1966), Chodorow (1978) e Badinter (1992), que discutem a construção do gênero do ponto de vista da psicanálise. Conforme demarca Greenson (1966) (colaborador de Stoller), a grande dificuldade na assunção da masculinidade para o menino é o fato de que ele se constitui subjetivamente, num primeiro momento, desde uma identificação com o campo do feminino em decorrência de sua relação estreita e gratificante com sua mãe. A construção da masculinidade, por conta disso, envolveria não apenas o movimento positivo de identificação com o universo masculino, mas também e, fundamentalmente, num esforço no sentido da negação da identificação feminina primária.

Parece que, assim como a menina tem um problema especial no estabelecimento das relações objetais por ter que mudar o gênero de seu objeto de amor, o menino, por sua vez, tem um problema especial na construção de uma identidade de gênero por ter que mudar o objeto original de sua identificação (Greenson, 1966, p. 402. Tradução minha). ${ }^{2}$

O rompimento com essa herança primeva é um processo doloroso e que acaba por caracterizar o complexo de Édipo não apenas como o período de abandono da mãe como objeto de amor, mas também como o momento em que ela deve deixar de ser objeto de identificação (Chodorow, 1978; Stoller, 1985). Assim, "esses dois fenômenos, des-identificar-se com a mãe e contra-

"It seems to me that just as the girl has a special problem in establishing object relations by having to change the gender of her love object, so the boy has a special problem in building a gender identity by having to change the original object of his identification" (Greenson, 1966, p. 402). 
identificar-se com o pai são processos interdependentes e formam uma série complementar" (Greenson, 1968, p. 372) ${ }^{3}$, sendo os comportamentos da mãe e do pai decisivos para a configuração dessa dinâmica.

As contribuições de Stoller e Greenson foram usadas por antropólogos como David Gilmore (1990) e Gilbert Herdt (1997) para dar uma explicação psicanalítica dos ritos de iniciação tão comuns em sociedades sem escrita, nas quais os meninos, para serem considerados homens, têm que passar por uma série de provas de resistência física e mental. A existência de uma relação simbiótica entre mãe e bebê na primeira infância justificaria os temores, existentes nessas tribos, de que, se o menino não fosse separado radicalmente de sua mãe, não conseguiria exercer o papel masculino que sua sociedade espera dele, principalmente no caso de tribos nas quais a guerra é uma ameaça constante e a caça é fundamental para a sobrevivência. Nessas sociedades, prevalece uma concepção de que a masculinidade não é um estado natural e que a excessiva presença feminina contamina o menino, impedindo-o de se tornar viril (Herdt, 1997). Por conta disso, a partir de uma certa idade, variante de sociedade para sociedade (comumente em torno de 7 anos), eles são separados de suas mães e de todas as mulheres, ficam por anos distantes delas, sendo submetidos a testes enormemente sacrificantes até que, já adultos, podem voltar a ter contato com pessoas do sexo feminino, já não mais como crianças, mas como homens (Gilmore, 1990). Tal provação demonstra, segundo Badinter (1992), que a masculinidade é um ideal que o sujeito de sexo masculino jamais se sente seguro de ter realmente alcançado.

Contemporaneamente, a tese desenvolvida nos anos 60 por Stoller e Greenson tem sido revista e criticada por Michael J. Diamond (2004, 2008, 2009) psicanalista americano que argumenta terem Stoller e Greenson se equivocado ao afirmarem que, para a construção da identidade de gênero masculina, é primordial que o menino se desidentifique de sua mãe e se contraidentifique com seu pai ou substituto (Diamond, 2004). Segundo Diamond (2004), não é necessário que o isso aconteça, pois a identidade de gênero masculina é múltipla e deve acolher também a herança materna. Nesse sentido, a análise stolleriana falharia ao não apontar para a necessidade e mesmo para a inevitabilidade da identificação do menino com ambos os progenitores no pré-Édipo. Os casos nos quais a "des-identificação" se apresenta como inevitável caracterizariam mais propriamente uma dinâmica patológica de constituição subjetiva na qual a figura materna veda a entrada de outros personagens na história primitiva da criança, assumindo um caráter

\footnotetext{
"This two phenomena, dis-identifying from mother and counter-identifying with father are interdependent and form a complementary series" (Greenson, 1968, p. 372).
} 
intrusivo e dificultando, consequentemente, o rompimento desse vínculo primitivo. Nessas situações, a desidentificação se apresenta como uma defesa narcísea, que costuma ter como efeito a constituição, pelo menino, de um superego severo e a solidificação de um conceito estreito e rígido de masculinidade, capazes de acarretarem, futuramente, dificuldades no desenvolvimento da afetividade e especificamente, empecilhos na esfera dos relacionamentos amorosos. Diamond (2004) enfatiza que a fase de separação-individuação (Mahler, 1975) se constitui como um momento delicado, pois, assim como é perniciosa a continuidade da ligação estreita entre mãe e filho, uma ruptura muito abrupta, da mesma forma, pode ser demasiadamente dolorosa e igualmente prejudicial, podendo gerar, também, sentimentos hostis em relação ao feminino como consequência.

Por conta disso, Diamond considera que, ao invés da oposição que caracteriza o movimento para des-identificar-se proposto por Greenson (1968) e Stoller (1968), deve ocorrer uma progressiva diferenciação entre mãe e filho. Assim sendo, "não é o repúdio pelo menino de sua identificação materna que é crucial para o estabelecimento de sua masculinidade" (Diamond, 2004, p. 364. Tradução minha) ${ }^{4}$. O fundamental é que se constitua, nesse momento, uma relação afetivamente sólida com ambos os cuidadores e que o processo de separação possa ser vivido de forma mais fluida conforme os dois genitores (ou substitutos) sejam suficientemente atentos às vicissitudes desse enquadre e saibam reconhecer as peculiaridades e as necessidades da criança de sexo masculino.

Um pai atencioso e protetor, tipicamente em conjunção com uma mãe suficientemente atenta e capaz de reconhecer a masculinidade de seu filho, ajuda a mitigar a severidade daquilo que poderia ser traumático para o menino que está envolto no processo de separação-individuação 5 (Diamond, 2004, p. 362. Tradução minha).

Para Diamond (2004), a atuação do pai ou de seu substituto no pré-Édipo é fundamental no momento do estabelecimento do núcleo da identidade de gênero do menino, pois, estando ele presente, poderá

\footnotetext{
"[...] not the boy disavowal of his maternal identifications that is crucial to establishing his masculinity" (Diamond, 2004, p. 364).

A watchful, proctetive father, typically in conjunction with a sufficiently attuned mother able to recognize her son's masculinity, helps to mitigate the severity of what might be potentially traumatizing for the boy who is engaged in the separation-individuation process (Diamond, 2004, p. 362).
} 
apresentar-se como um importante locus para a identificação e tornar-se-á consequentemente um modelo a mais, além do materno. Havendo essa tríade e sendo os genitores suficientemente atentos às necessidades da criança, não será preciso que ela repudie ou renuncie à herança de sua mãe. Contrariamente será sobretudo extremamente positiva a possibilidade do menino condensar os dois referenciais, pois isso tornará possível a criação das bases de um mais seguro sentimento de masculinidade e a ampliação das múltiplas possibilidades no campo de gênero. Dessa forma, seriam estabelecidos alicerces seguros que possibilitariam a emergência de um senso de masculinidade mais flexível e menos reativo aos aspectos ditos femininos do psiquismo. Em resumo, para Diamond, o alcance da masculinidade é um processo longo e bastante complexo que o homem só costuma conquistar de forma mais plena na meia-idade, quando passa a estar mais aberto à afetividade e menos preocupado em reafirmar sua virilidade (Diamond, 2009).

A posição de Diamond (2004, 2008, 2009) difere da leitura psicanalítica clássica que entende o masculino e o feminino com base em oposições estanques. Consideramos que a tese da desidentificação stolleriana endossa esse tipo de concepção binária e é tributária da divisão de papéis sexuais, historicamente construída. Postular a necessidade de uma desidentificação materna significa aceitar que o sujeito de sexo masculino deve se constituir como um oposto ou um complemento à mulher. Diamond (2008), embora não questione a diferença sexual postulada pela psicanálise, como fazem certos psicanalistas (Néri, 2003; Arán, 2006; Peixoto Jr., 2000; 2008), se diferencia de Stoller ao apontar para a necessidade de uma flexibilização do processo de constituição da masculinidade.

Com todas as transformações nas relações de gênero ocorridas nos últimos 40 anos, não seria demais, de fato, esperar que o modelo de masculinidade socialmente desejado se aproximasse da forma múltipla proposta por Diamond (2008). Uma sociedade mais pluralista, como parece ser a sociedade contemporânea, permite ao homem se libertar da exigência de seguir um único referencial normativo para constituir-se. Nesse sentido, a visada de Diamond parece ser a que mais se aproxima daquela postulada por Judith Butler em Problemas de gênero (1990) pelo fato de ambos ressaltarem a importância da abertura da subjetividade ao plural e não entenderem o masculino e o feminino desde divisões estanques. Em Diamond (2004, 2009), essa questão é trabalhada principalmente com base na importância concedida à dupla identificação 
com os genitores sem que a postulação da diferença sexual seja revista, e é justamente esse o ponto central de distanciamento entre ambos ${ }^{6}$. Um outro ponto em relação ao qual suas hipóteses divergem diz respeito à constituição da identidade de gênero que Butler entende como uma ficção instável, derivada da repetição performativa efeito de injunçôes culturais. Para Diamond, por outro lado, é possível al cançar uma certa coerência e estabilidade identitária masculina, mesmo que múltipla, sustentada pelo acolhimento da dupla herança.

Tornar-se homem tem cada vez menos se confundido com adotar uma identidade uniforme, que remete a um conjunto igualmente uniforme de representações. A abertura à pluralidade e à invenção de si têm sido projetos que paulatinamente têm se tornados mais possíveis ao sujeito de sexo masculino. Nesse sentido, podemos pensar que, em vez de instaurar uma crise no universo da masculinidade, o momento atual pode ser especialmente profícuo por abrir novas possibilidades de se reinventar o dito "sexo forte". O movimento de questionamento dos estereótipos da virilidade clássica pode ser, então, particularmente válido por abrir aos homens novos meios para a constituição de uma existência singular e para a emergência de uma subjetividade mais criativa. O abandono do esforço diário para se autoafirmar como viril, que tão marcadamente caracterizou o cotidiano dos sujeitos de sexo masculino, pode favorecer o deslocamento dessa energia para o campo da afetividade e possibilitar a maior exploração de funções antes menos valorizadas pelos homens, como a paternidade. Desse modo, o momento contemporâneo pode ser benéfico para os homens por permitir-lhe uma reinvenção mais livre dos estereótipos de gênero aprisionadores por tanto tempo propagados pelas sociedades ocidentais.

\section{Referências}

Arán, M. (2006). O destino da diferença sexual na sociedade contemporânea. In: Arán, M. $O$ avesso do avesso: feminilidade e novas formas de subjetivação. Rio de Janeiro: Garamond.

Badinter, E. (1992). XY: sobre a identidade masculina. Rio de Janeiro. Nova Fronteira.

\footnotetext{
De fato, para certos autores (Arán 2006; Néri, 2003; Peixoto Jr., 2000) as bases lançadas por Freud e Lacan para a conceituação da diferença sexual limitam o pensamento psicanalítico, o qual, para ser compatível com a proposta foucaultiana de fazer da vida uma obra de arte, deve se desvencilhar dessas balizas. Recorrer à teoria fálico-edípica para entender o gênero seria erigir uma nova metafísica e trazer à boca de cena o universalismo, mantendo simultaneamente uma perspectiva binária.
} 
Bento, B. (2006). Estudos de gênero: o universal, o relacional e o plural. In: Bento, B. A reinvenção do corpo: sexualidade e gênero na experiência transexual. Rio de Janeiro: Garamond, 2006. (Coleção sexualidade, gênero e sociedade).

Beauvoir, S. (1949). O segundo sexo. Rio de Janeiro: Nova Fronteira.

Bourdieu, P. (1998). A dominação masculina. Rio de Janeiro: Bertrand Brasil.

Butler, J. (1990). Problemas de gênero: feminismo e subversão da identidade. Rio de Janeiro: Civilização Brasileira.

Ceccarelli, P. (1998). A construção da masculinidade. Revista Percurso, (19): 49-56.

Chodorow, N. (1978). A psicanálise da maternidade. Rio de Janeiro: Rosa dos Ventos.

Diamond, M. (2004). The shaping of masculinity: revisioning boys turning away from their mothers to construct male gender identity. International Journal of Psychoanalysis, 85 (2): 359-380.

Diamond, M. (2004). Accessing the multitude within: a psychoanalytic perspective on the transformation of masculinity at mid-life. International Journal of Psychoanalysis, 85 (1): 45-64.

Diamond, M. (2008). Tal pai, tal filho: como pais e filhos influenciam uns aos outros ao longo da vida. São Paulo: Academia de Inteligência.

Diamond, M. (2009). Masculinity and its discontents: making room for the "Mother" inside the Male - An essential achievement for healthy male gender identity. In: Reis, B.; Grossmark, R. (org.). (2009). Heterossexual masculinities: contemporary perspectives from psychoanalytic gender theory. New York: Routledge.

Ferenczi, S. (1924). Thalassa: ensaio sobre a teoria psicanalítica da genitalidade. Rio de Janeiro: Martins Fontes.

Fortes, I. (1999). No amor: ser um ou ser dois? Tempo Psicanalitico, (31), 121-141.

Foucault, M. (1979). Microfísica do poder. 21. ed. São Paulo: Graal. 
Freud, S. (1976). Rascunho K. As neuroses de defesa. Edição standard das obras psicológicas completas de Sigmund Freud. (v. I, pp. 307-318). Rio de Janeiro: Imago. (Texto originalmente publicado em 1894).

Freud, S. (1976). Três ensaios sobre a sexualidade. Edição standard das obras psicológicas completas de Sigmund Freud. (v. VII, pp. 117-230). Rio de Janeiro: Imago. (Texto originalmente publicado em 1905).

Freud, S. (1976). Sobre a tendência universal à depreciação na esfera do amor. Edição standard das obras psicológicas completas de Sigmund Freud. (v. XI, pp. 163-173). Rio de Janeiro: Imago. (Texto originalmente publicado em 1912).

Freud, S. (1976). Sobre o narcisismo: uma introdução. Edição standard das obras psicológicas completas de Sigmund Freud. (v. XIII, pp. 83-119). Rio de Janeiro: Imago. (Texto originalmente publicado em 1914).

Freud, S. (1976). Repressão. Edição standard das obras psicológicas completas de Sigmund Freud. (v. XIII, pp. 169-189). Rio de Janeiro: Imago. (Texto originalmente publicado em 1915).

Freud, S. (1976). O inconsciente. Edição standard das obras psicológicas completas de Sigmund Freud. (v. XIII, pp. 183-251). Rio de Janeiro: Imago. (Texto originalmente publicado em 1915).

Freud, S. (1976). Conferências introdutórias sobre psicanálise. Edição standard das obras psicológicas completas de Sigmund Freud. (v. XVI, pp. 481-502). Rio de Janeiro: Imago. (Texto originalmente publicado em 1916).

Freud, S. (1976). A organização genital infantil: uma interpolação na teoria da sexualidade. Edição standard das obras psicológicas completas de Sigmund Freud. (v. XIX, pp. 175-184). Rio de Janeiro: Imago. (Texto originalmente publicado em 1923).

Freud, S. (1976). Neurose e psicose. Edição standard das obras psicológicas completas de Sigmund Freud. (v. XIX, pp. 185-193). Rio de Janeiro: Imago. (Texto originalmente publicado em 1924).

Freud, S. (1976). A dissolução do complexo de Édipo. Edição standard das obras psicológicas completas de Sigmund Freud. (v. XIX, pp. 214-224). Rio de Janeiro: Imago. (Texto originalmente publicado em 1924).

Freud, S. (1976). Algumas consequências psíquicas da distinção anatômica 
entre os sexos. Edição standard das obras psicológicas completas de Sigmund Freud. (v. XIX, pp. 301-307). Rio de Janeiro: Imago. (Texto originalmente publicado em 1925).

Freud, S. (1976). O mal estar na civilização. Edição standard das obras psicológicas completas de Sigmund Freud. (v. XXI, pp. 81-171). Rio de Janeiro: Imago. (Texto originalmente publicado em 1930).

Freud, S. (1976). Sexualidade feminina. Edição standard das obras psicológicas completas de Sigmund Freud. (v. XXI, pp. 255-279). Rio de Janeiro: Imago. (Texto originalmente publicado em 1931).

Giddens, A. (1999). Modernidade e identidade. Rio de Janeiro: Jorge Zahar.

Gilmore, D. (1990). Manhood in the making: cultural concepts of masculinity. New York: Vail-Ballou Press.

Greenson, R. (1966). A transvestite boy and a hypothesis. International Journal of psychoanalysis, (47), 396-403.

Greenson, R. (1968). Disidentifying from mother: its special importance for the boy. London. International journal of psychoanalysis, (49), 370-374.

Heilborn, M. L. (2004). Dois é par: gênero e identidade sexual em contexto igualitário. Rio de Janeiro: Garamond.

Herdt, G. (1997). Male birth-giving in the cultural imagination of the Sambia. Psychoanalytic Review, (84), 217-226.

Kehl, M. (1996). A minima diferença. Rio de Janeiro: Imago.

Kumar, K. (1995). Da sociedade pós-industrial à pós-moderna. Rio de Janeiro: Jorge Zahar.

Lacan, J. (1958). O seminário, livro 5: as formaçôes do inconsciente. Rio de Janeiro: Jorge Zahar.

Lyotard, J-F. (1979). A condição pós-moderna. Rio de Janeiro: José Olympio.

Machado, L. (1992). Feminismo, academia e interdisciplinaridade. In: Costa, A.; Bruschini, C. (org.). Uma questão de gênero. Rio de Janeiro: Rosa dos Tempos.

Mendlowicz, E. (1995). Tornar-se homem. Tempo psicanalítico, 10 (28), 165175. 
Neri, R. (2003). Psicanálise e as novas formas de subjetivação e de sexualidade. A construção fálico-edípica: uma teoria da diferença? Estados Gerais da Psicanálise. Segundo Encontro Mundial. Rio de Janeiro.

Peixoto Junior, C. A. (2000). A estética da existência e o cuidado de si como formas de subjetivação. Tempo psicanalítico, (32) 97-107.

Peixoto Junior, C. A. (2008). Singularidade e subjetivação. Ensaios sobre clínica e cultura. Rio de Janeiro: 7 Letras; Editora PUC-Rio.

Pinker, S. (2006). The blank slate. In: The General Psychologist, (16), 1-8.

Platão. (1995). O banquete; ou, Do amor. Rio de Janeiro. Bertrand Brasil. Ribeiro, P. (2000). O problema da identificação em Freud. São Paulo. Escuta.

Reis, B. (2009). Names of the father. In: REIS, B.; Grossmark, R. (org.). Heterossexual masculinities: contemporary. New York: Routledge.

Russo, J.; Ponciano, E. (2002). O sujeito da neurociência: da naturalização. Perspectives from psychoanalytic gender theory. New York: Routeledge.

Russo, J.; Ponciano, E. (2002). O sujeito da neurociência: da naturalização do homem ao Re-encantamento da natureza. Physis: Revista de Saúde Coletiva, 2 (12), 345-373.

Scott, J. (1986). Gender: an useful category of historical analysis. The American Historical Review, 5 (91), 1053-1075.

Sorj, B. (1992). O feminismo na encruzilhada da Modernidade e Pósmodernidade. In: Costa, A. \& Bruschini, C. (org.). Uma questão de gênero. Rio de Janeiro: Rosa dos Tempos.

Silva, A. (2004). Gênero: uma categoria útil para o estudo do corpo e da saúde? Labrys, Estudos feministas, (5).

Silva, G. J. (2004). Gênero em questão: apontamentos para uma discussão teórica. Mneme - Revista Virtual de humanidades, 5 (10), 1-8.

Stoller, R. (1985). Masculinidade e feminilidade: apresentaçôes de gênero. Porto Alegre: Artes Médicas.

Winnicott, D. (1956). Da pediatria à psicanálise. Rio de Janeiro: Francisco Alves. 